\title{
When Should Sedation or Neuromuscular Blockade Be Used During Mechanical Ventilation?
}

\author{
Suzanne Bennett MD and William E Hurford MD
}

\author{
Introduction \\ The Triad of Agitation \\ Pain \\ Anxiety \\ Delirium \\ Deep Sedation and Anesthesia \\ Neuromuscular Blocking Agents \\ Summary
}

\begin{abstract}
Sedation has become an important part of critical care practice in minimizing patient discomfort and agitation during mechanical ventilation. Pain, anxiety, and delirium form a triad of factors that can lead to agitation. Achieving and maintaining an optimal level of comfort and safety in the intensive care unit plays an essential part in caring for critically ill patients. Sedatives, opioids, and neuromuscular blocking agents are commonly used in the intensive care unit. The goal of therapy should be directed toward a specific indication, not simply to provide restraint. Standard rating scales and unit-based guidelines facilitate the proper use of sedation and neuromuscular blocking agents. The goal of sedation is a calm, comfortable patient who can easily be aroused and who can tolerate mechanical ventilation and procedures required for their care. Key words: sedation; neuromuscular blockade; agitation. [Respir Care 2011;56(2):168-176. () 2011 Daedalus Enterprises]
\end{abstract}

\section{Introduction}

Sedatives, opioids, and neuromuscular blocking agents (NMBAs) are commonly used in the intensive care unit (ICU). Utilization of these treatment modalities should be

Suzanne Bennett MD and William E Hurford MD are affiliated with the Department of Anesthesiology, University of Cincinnati, Cincinnati, Ohio.

The authors have disclosed no conflicts of interest.

Dr Hurford presented a version of this paper at the 46th RESPIRATORY CARE Journal Conference, "Patient-Ventilator Interaction," held March 1921, 2010, in Cancún, Quintana Roo, Mexico.

Correspondence: Suzanne Bennett MD, Department of Anesthesiology, University of Cincinnati, PO Box 670531, 231 Albert Sabin Way, Cincinnati OH 45267-0531. E-mail: suzanne.bennett@uc.edu.

DOI: $10.4187 /$ respcare.01095 directed toward a specific indication, with the ultimate goal of achieving comfort and maintaining safety in the critically ill patient.

Sedation has become an inseparable part of critical care practice in minimizing patient discomfort and agitation; however, sedatives can have adverse effects that prolong mechanical ventilation and ICU stay. The dilemma we face in caring for critically ill patients is the balance between treating agitation while minimizing the adverse outcomes from our therapies. Mechanically ventilated patients receiving continuous intravenous sedation have a prolonged duration of mechanical ventilation, ICU stay, and hospital stay, when compared to those receiving no or intermittent sedation. ${ }^{1,2}$ Kollef and coworkers demonstrated this problem in an observational study with 242 mechanically ventilated patients in a medical ICU, in which $38 \%$ of the patients received continuous infusions of lorazepam and/or fentanyl, 26\% received intermittent bolus therapy, and 35\% received no sedation. Patients who received continu- 


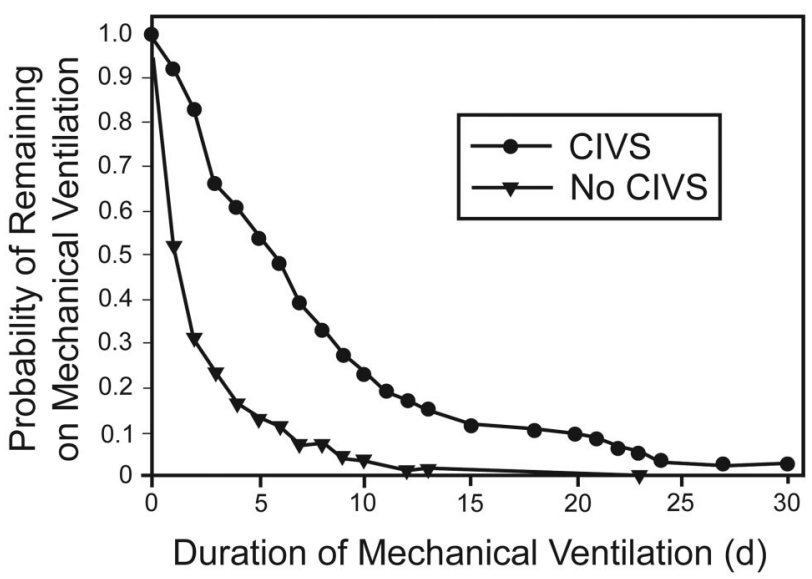

Fig. 1. Kaplan-Meier curves for patients receiving versus not receiving continuous intravenous sedation (CIVS). (Adapted from Reference 1, with permission.)

ous infusion of sedatives had significantly longer mechanical ventilation, ICU stay, and hospital stay (Fig. 1). ${ }^{1}$ More recently, in a retrospective analysis of 549 patients with acute lung injury and acute respiratory distress syndrome enrolled in the Assessment of Low Tidal Volume and Elevated End-Expiratory Volume to Obviate Lung Injury (ALVEOLI) trial, the use of benzodiazepines and opioids was associated with longer mechanical ventilation and time to successful 2-hour spontaneous breathing trial. ${ }^{2}$

\section{The Triad of Agitation}

The ultimate goal of ICU sedation is to minimize agitation to allow the patient to be calm and comfortable throughout the ICU stay, while minimizing sleep/wake cycle disturbances and complications. Agitation is a nonspecific symptom resulting from any type of internal discomfort. Agitation is extremely common in ICU patients of all ages, occurring at least once in $71 \%$ patients in medical-surgical ICUs. ${ }^{3}$ The "triad of agitation" consists of pain, delirium, and anxiety, and each of these 3 internal discomforts can result in an agitated patient (Fig. 2). Agitation alone is associated with more complications and longer stay. In a prospective cohort study of a single medical ICU by Woods and colleagues, 23 of the 143 mechanically ventilated patients showed severe agitation that was associated with longer median ICU stay (12 d [range 2-40 d] versus $5 \mathrm{~d}$ [range 1-35 d]), longer median mechanical ventilation (14 d [range 2-44d] versus $6 \mathrm{~d}$ [range 1-43]), and percent of self-extubations ( $26 \%$ vs $6 \%$ ). ${ }^{4}$ Pain, delirium, and anxiety must all be assessed and treated to reduce the critically ill patient's agitation. The use of standard rating scales and unit-based guidelines form the foundation for the assessment and treatment of agitation with sedation.

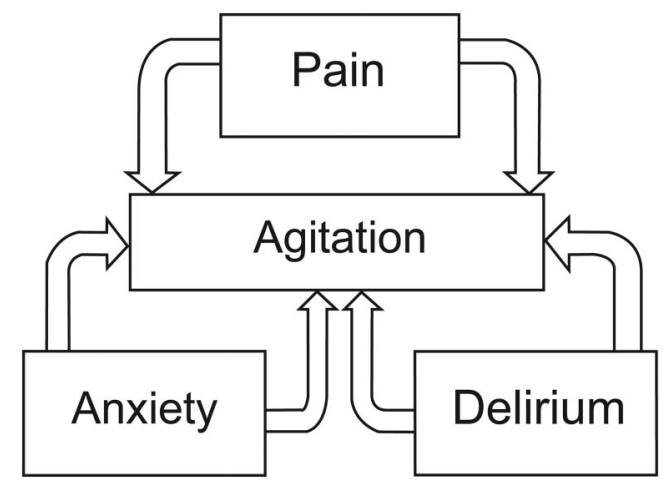

Fig. 2. Triad of agitation

Table 1. Advantages and Disadvantages of Opioids

\begin{tabular}{ll}
\hline \hline \multicolumn{1}{c}{ Advantages } & \multicolumn{1}{c}{ Disadvantages } \\
\hline Analgesia & Decreased gastrointestinal motility \\
Sedation & Sedation \\
Respiratory depression & Respiratory depression \\
Antitussive & Chest-wall rigidity \\
& No amnesia \\
& Tolerance \\
\hline
\end{tabular}

\section{Pain}

Pain often goes unrecognized and is undertreated in the critical-care setting. Pain at rest is common in surgical, trauma, and medical ICU patients. Chanques and coworkers reported, in a study with 154 trauma/surgical and 76 medical ICU patients, that $51 \%$ of patients reported substantial pain. There was no difference in the incidence of pain between medical and surgical patients. Indeed, the medical patients reported higher pain scores, perhaps because they were less likely to receive preventive analgesics $(63 \%$ of medical patients received no preventive analgesics, compared to only $36 \%$ of the surgical patients.). ${ }^{5}$ A multimodal approach to the treatment of pain appears to be the best approach. Nonpharmacologic modalities, such as splinting of fractures and proper positioning in bed, should be addressed first to minimize discomfort. Opioids, however, remain the most common pharmacologic therapy of severe pain in ICU patients. Opioids provide analgesia, but also have deleterious effects (Table 1). Alternatives to opioids include non-steroidal anti-inflammatory drugs, regional analgesia, and adjunctive medications, such as gabapentin and pregabalin in the treatment of neuropathic pain. Both epidural analgesia and continuous/single-shot nerve blocks have been used as an alternative to intravenous opioids. In a prospective observational study of 201 patients who underwent thoracoabdominal esophagectomy, for example, patients who received thoracic epidural analgesia had less pain and fewer adverse effects such as 
Table 2. Postoperative Analgesia Adverse Effects

\begin{tabular}{lccc}
\hline \hline & $\begin{array}{c}\text { Thoracic } \\
\text { Epidural } \\
\text { no. (\%) }\end{array}$ & $\begin{array}{c}\text { Intravenous } \\
\text { Morphine } \\
\text { no. (\%) }\end{array}$ & $P$ \\
\hline Sedation & $2(1)$ & $6(17)$ & $<.001$ \\
Respiratory depression & $0(0)$ & $2(6)$ & .03 \\
Hallucinations & $4(2)$ & $4(11)$ & .03 \\
Confusion & $0(0)$ & $4(11)$ & .001 \\
(Data from Reference 6.) & & & \\
\hline
\end{tabular}

respiratory depression, hallucinations, or confusion, compared to patients receiving patient-controlled analgesia with morphine (Table 2). ${ }^{6}$

\section{Anxiety}

If agitation persists once a patient's pain has been addressed, anxiety and delirium must be evaluated and treated. Anxiety is an abnormal feeling of apprehension, uncertainty, and fear. Historically, benzodiazepines have been the first line of therapy in the ICU setting for sedating mechanically ventilated patients. ${ }^{7}$ Typical benzodiazepines used in the ICU are midazolam and lorazepam. Midazolam has a rapid onset and short duration with single doses. Midazolam, however, has active metabolites that can accumulate, resulting in prolonged sedative effects in patients, in particular in those who are obese, hypoalbuminemic, or have renal dysfunction. Lorazepam has a slower onset of action and a half-life of $8-15$ hours, but no active metabolites. A drawback to the use of lorazepam is that it is mixed in a propylene glycol solvent, which can produce lactic acidosis, acute tubular necrosis, and a hyperosmolar state when used in high doses. Benzodiazepine use has been associated with longer ICU stay and longer mechanical ventilation, ${ }^{1}$ and can increase the risk of delirium. Pandharipande and coworkers, in a cohort study with 198 mechanically ventilated patients admitted to the medical and coronary ICUs, reported that lorazepam administration was an independent risk factor for the development of delirium (odds ratio 1.2, 95\% CI 1.1-1.4, $P=.003$ ). ${ }^{8}$

Withholding sedation may actually improve outcomes. In a randomized trial conducted by Strøm and colleagues, critically ill patients receiving mechanical ventilation and no routine sedation (although receiving bolus intravenous morphine) had more ventilator-free days (mean $13.6 \mathrm{~d}$ vs $9.6 \mathrm{~d}$ ) and shorter ICU stay (median $13.1 \mathrm{~d}$ vs $22.8 \mathrm{~d}$ ) than patients receiving propofol infusions for the first 48 hours and subsequently midazolam with daily interruption of sedation. The patients receiving no routine sedation, however, experienced agitated delirium more frequently $(20 \%$ vs $7 \%$ ) and required increased work loads on the part of

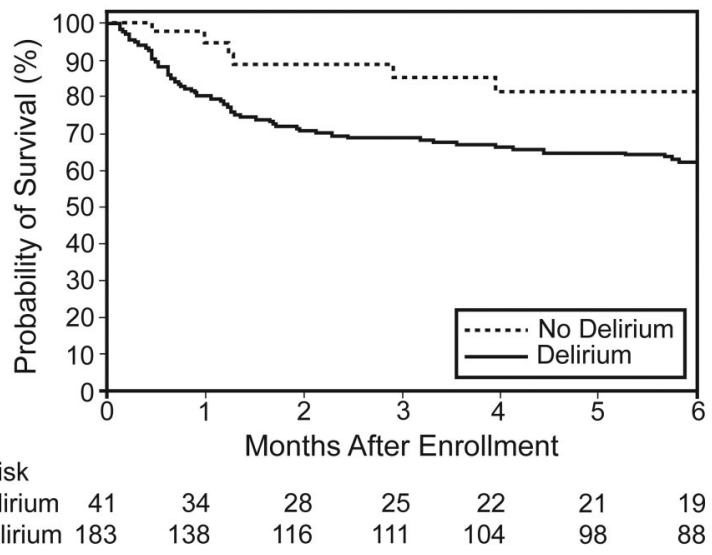

Fig. 3. Kaplan-Meier analysis of delirium in the intensive care unit and 6-month survival. (Adapted from Reference 13, with permission.)

caregivers. ${ }^{9}$ A balance must be achieved between minimizing sedation and avoiding delirium. Cautious treatment of anxiety and avoidance of continuous infusions of benzodiazepines are necessary to reduce agitation.

\section{Delirium}

Delirium, another factor contributing to agitation, must be identified and treated promptly. Delirium is a form of brain dysfunction characterized by an acute and fluctuating course of impaired cognitive function and inattention, so that a patient's ability to receive, process, and store information is impaired. ${ }^{10}$ The more commonly discussed delirium is when the patient displays psychomotor agitation and hallucinations, the so-called "hyperactive" delirium. However, the more common delirium, "hypoactive" delirium, manifested as withdrawn, decreased mental activity and inattention, is often under-diagnosed and more deleterious in the long term for the patient. ${ }^{11,12}$ Delirium is devastating for the patient and a major public health problem. Delirium increases complications, ICU stay, and hospital costs. Twenty-five percent of elderly delirious patients are dead within 6 months. The American Association of Retired Persons considers delirium as one of the 6 leading causes of preventable injury in those greater than 65 years of age. Ely and colleagues, in a prospective cohort study of 275 mechanically ventilated patients admitted to adult medical and coronary ICUs, reported that $81.7 \%$ of patients developed delirium during their ICU stay. ${ }^{13}$ Those patients who developed delirium had a higher 6 -month mortality ( $34 \%$ vs $15 \%, P=.03$ ) and spent 10 days longer in the hospital than those who did not develop delirium (Fig. 3 and 4). ${ }^{13}$ The cause of delirium is multifactorial. Risk factors include cognitive impairment, sleep deprivation, immobility, visual and hearing impairment, and dehydration (Table 3). ${ }^{14}$ The higher the number of risk 


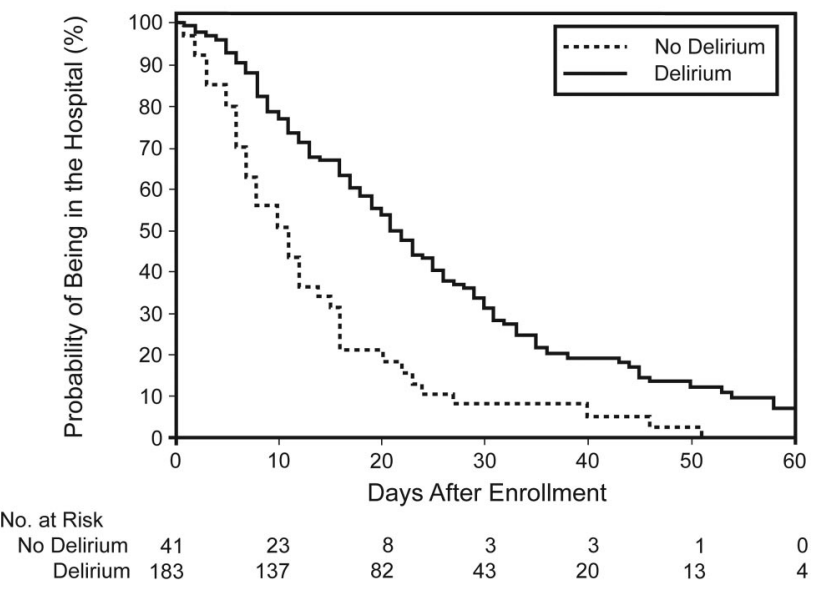

Fig. 4. Kaplan-Meier analysis of delirium in the intensive care unit and hospital stay. (Adapted from Reference 13, with permission.)

factors, the greater the risk of delirium. ${ }^{15,16}$ Inouye and colleagues, in a controlled clinical trial of 852 hospitalized patients age $\geq 70$ years, reported that, when preventive interventions were targeted at those risk factors, delirium developed less often in the intervention group than in the usual-care group $(9.9 \%$ vs $15 \%, P=.02)$, patients experienced fewer total days with delirium $(105 \mathrm{~d}$ vs $161 \mathrm{~d}$, $P=.02)$, and the total number of episodes of delirium (62 vs $90, P=.03$ ) were lower in the intervention group (see Table 3, Fig. 5). ${ }^{14}$ Early initiation of physical and occupational therapy also appears to reduce delirium. Schweickert and coworkers, in a study of 104 sedated, mechanically ventilated ICU patients randomized to physical and occupational therapy during daily interruption of sedation or daily interruption alone, found that patients in the intervention group had shorter duration of delirium (median $2.0 \mathrm{~d}$, interquartile range [IQR] $0.0-6.0 \mathrm{~d}$ vs $4.0 \mathrm{~d}$, IQR $2.0-8.0 \mathrm{~d}, P=.02$ ), and more ventilator-free days ( $23.5 \mathrm{~d}$, IQR $7.4-25.6 \mathrm{~d}$ vs $21.1 \mathrm{~d}$, IQR $0.0-23.8 \mathrm{~d}, P=.05$ ) during the 28-day follow-up period than did controls. ${ }^{17}$

Preventing delirium by identifying and modifying risk factors is the best treatment. However, consistently assessing for delirium with a validated assessment tool can lead to prompt identification and treatment with antipsychotic pharmacotherapy, if appropriate. The detection of delirium is best identified by utilizing validated assessment tools, such as the Confusion Assessment Method for the ICU (CAM-ICU) and the Intensive Care Delirium Screening Checklist (ICDSC). ${ }^{10,18}$ The severity of delirium can be measured using the Delirium Detection Score (DDS). ${ }^{19}$ The CAM-ICU, adapted for use with even the most difficult ICU patients (nonverbal, mechanically ventilated, demented), is widely used and easily performed in less than 2 min. ${ }^{10,20}$ ICDSC, a bedside screening tool for delirium based on information from the previous 24 hours, is an-
Table 3. Risk Factors and Examples of Interventions for Delirium

\begin{tabular}{ll}
\hline \hline \multicolumn{1}{c}{ Risk Factor } & \multicolumn{1}{c}{ Examples of Interventions } \\
\hline Cognitive impairment & $\begin{array}{l}\text { Frequent reorientation } \\
\text { Provide stimulating activities } \\
\text { Noise-reduction strategies } \\
\text { Sleep deprivation }\end{array}$ \\
Schedule adjustments \\
Early mobilization \\
Ammobility & $\begin{array}{l}\text { Active range of motion } \\
\text { Minimize catheters and physical restraints }\end{array}$ \\
& $\begin{array}{l}\text { Provide glasses and adaptive equipment } \\
\text { Provide hearing aids } \\
\text { Special communication techniques } \\
\text { Visual impairment }\end{array}$ \\
Hearing impairment & \\
Dehydration & \\
\hline (Data from Reference 14.) & \\
\hline
\end{tabular}

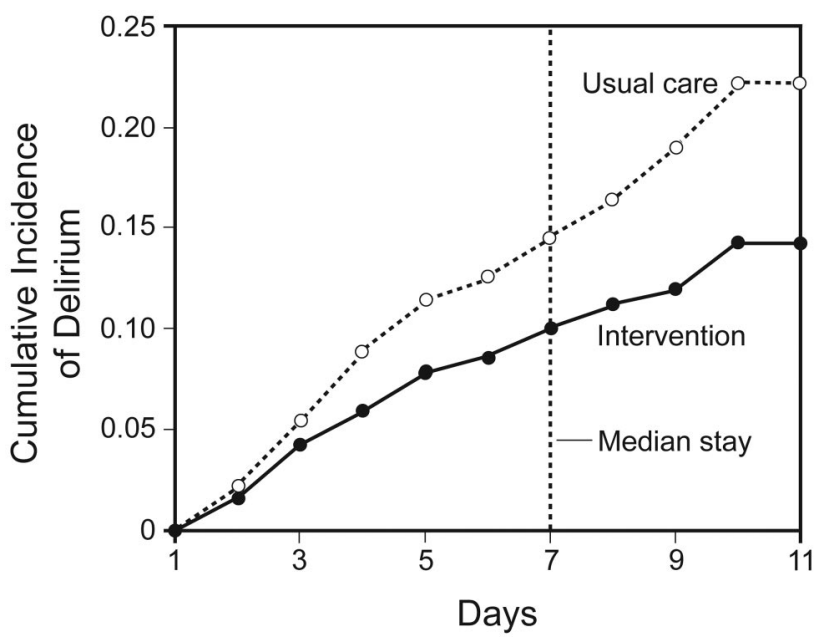

Fig. 5. Cumulative incidence of delirium according to study group. (Adapted from Reference 14, with permission.)

other well validated screening tool, utilizing an 8-item checklist based on the Diagnostic and Statistical Manual of Mental Disorders (DSM-IV) criteria. ${ }^{18}$ The key to successful management of delirium is prompt recognition utilizing a validated screening tool; then efforts should be made at identifying the etiology and pharmacotherapy, if appropriate.

Once assessment and removal of any of the patient's current medications that could be contributing to the delirium have been completed, the clinician may utilize alternate pharmacotherapy in the treatment of delirium. To date there are no Food and Drug Administration approved medications for the treatment of delirium. The Society of Critical Care Medicine guidelines recommend haloperidol for the treatment of delirium as level $\mathrm{C}$ data. ${ }^{7}$ There are no randomized control trials evaluating the use of haloperidol in mechanically ventilated patients. Both haloperidol and 
quetiapine have not been studied extensively in the ICU population. In a randomized placebo-controlled study of 430 hip-surgery patients age $\geq 70$ years, scheduled lowdose haloperidol initiated preoperatively decreased the severity (mean \pm SD highest Delirium Rating Scale [revised version 98] scores $14.4 \pm 3.4$ and $18.4 \pm 4.3$, respectively, $P<.001$ ) and duration of delirium (mean $5.4 \mathrm{~d}$ vs $11.8 \mathrm{~d}, P<.001)$ and hospital stay (mean $17.1 \pm 11.1 \mathrm{~d}$ and $22.6 \pm 16.7 \mathrm{~d}, P<.001$ ), compared with placebo. ${ }^{21}$ In a prospective multicenter randomized double-blind placebo-controlled pilot study with 36 ICU patients, quetiapine reduced the duration of delirium (36 h [IQR 12-87 h] vs $120 \mathrm{~h}$ [IQR $60-195 \mathrm{~h}$ ], $P=.006)$ and agitation (Sedation-Agitation Scale score $\geq 5)(6 \mathrm{~h}$ [IQR $0-38)$ versus $36 \mathrm{~h}$ [IQR $11-66 \mathrm{~h}], P=.02$ ). Patients were also more likely to be discharged to home or rehabilitation $(89 \%$ vs $56 \%, P=.06) .22$

\section{Deep Sedation and Anesthesia}

Achieving an adequate state of sedation and ventilator synchrony in some critically ill patients may require the use of anesthetics such as propofol, dexmedetomidine, and NMBAs. Patients receiving mechanical ventilation can be dyssynchronous with the ventilator, particularly when the severity of the patient's illness increases. Optimizing the patient-ventilator interaction to minimize asynchrony often includes sedation and sometimes NMBA. However, in randomized clinical trials involving patients with acute lung injury, receiving low-tidal-volume ventilation, sedation requirements were not increased. ${ }^{23,24}$ Pohlman and coworkers utilized deep sedation in their study of breathstacking during low-tidal-volume ventilation for acute lung injury and found that breath-stacking occurred despite the deep sedation. ${ }^{25}$ Thus, the ventilation mode is unlikely to be a determinant of the patient's sedation requirement. When asynchrony persists despite adjustments in ventilation mode and aggressive administration of analgesics and sedation, early administration of neuromuscular blockade may be necessary.

Propofol is a general anesthetic, administered intravenously via continuous infusion for sedation and amnesia. Propofol does not have any analgesic properties. The advantages of propofol are its rapid onset and short duration of action once discontinued. The disadvantages of propofol include bradycardia, a decrease in pre-load, hypertriglyceridemia, increased infection risk, and propofol-related infusion syndrome. ${ }^{26}$ In critically ill patients, propofol has less of an amnestic effect, and in some populations the rate of recovery when the drug is discontinued is much less variable when compared to midazolam. ${ }^{27,28}$ The administration of propofol is preferred when rapid awakening (extubation, neurologic assessment) is important; however, triglyceride concentrations should be monitored after 2 days

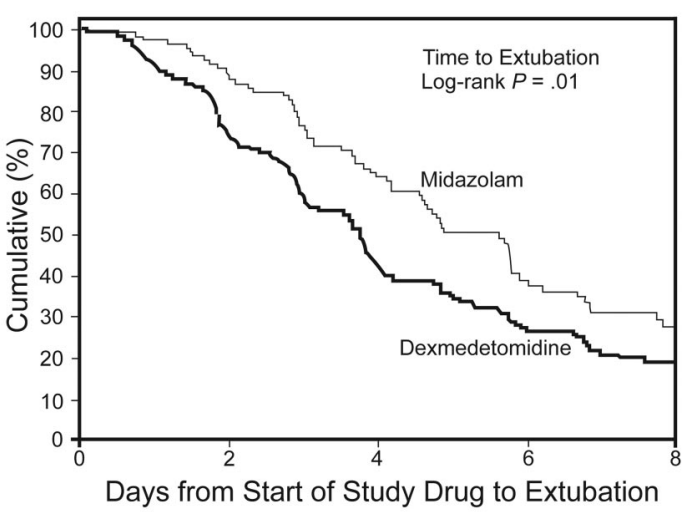

$\begin{array}{llrlll}\text { No. at Risk } & & & & \\ \text { Dexmedetomidine } & 244 & 153 & 73 & 40 & 21 \\ \text { Midazolam } & 122 & 91 & 60 & 29 & 16\end{array}$

Fig. 6. Time to extubation after which no re-intubation occurred among patients with dexmetatomidine versus midazolam. (Adapted from Reference 31, with permission.)

of infusion, and total caloric intake from propofol should be included in the nutrition caloric goals.

Dexmedetomidine is a potent alpha-2 agonist with sedative, anxiolytic, and mild analgesic properties. Initially, dexmedetomidine was Food and Drug Administration approved for short-term $(<24 \mathrm{~h})$ use in patients receiving mechanical ventilation. ${ }^{29}$ Under sedation with dexmedetomidine, patients will easily arouse with gentle stimulation, but will remain sedated when undisturbed. The adverse effects of dexmedetomidine include bradycardia, hypertension with bolus dosing, and hypotension with continuous infusion. In a prospective double-blind randomized study with 106 ICU patients, comparing dexmedetomidine (median $0.7 \mu \mathrm{g} / \mathrm{kg} / \mathrm{h}$ ) with continuous infusion lorazepam (median $3 \mathrm{mg} / \mathrm{h}$ ), sedation with dexmedetomidine resulted in more days alive without delirium and coma (median $7 \mathrm{~d}$ vs $3 \mathrm{~d}, P=.01)$, lower prevalence of coma (63\% vs $92 \%$, $P<.001)$, and greater success at meeting sedation goals, and no additional costs were seen in the design group, compared with lorazepam. ${ }^{30}$ Riker and coworkers, in a prospective double-blind randomized trial conducted in 68 centers in 5 countries, demonstrated that dexmedetomidine (mean dose $0.83 \pm 0.37 \mu \mathrm{g} / \mathrm{kg} / \mathrm{h}$ ), compared with continuous infusion midazolam $(3.2 \pm 1.5 \mathrm{mg} / \mathrm{h})$, decreased the incidence of delirium ( $54 \%$ vs $76.6 \%, P<.001)$, shortened mechanical ventilation ( $3.7 \mathrm{~d}$ versus $5.6 \mathrm{~d}, P=.01$ ), and decreased the incidence of tachycardia $(25.4 \%$ vs $44.3 \%, P<.001)$. Hypertension requiring treatment was more prevalent in the dexmedetomidine group (18.9\% vs $29.5 \%, P=.02$ ) (Fig. 6). ${ }^{31}$

\section{Neuromuscular Blocking Agents}

The use of NMBAs in mechanically ventilated critically ill patients remains quite common. In a prospective obser- 
vational study of 168 critically ill patients in 38 adult and pediatric ICUs in Canada, with the 2009 influenza A (H1N1) infection, $28 \%$ of patients who remained hypoxemic during mechanical ventilation were treated with NMBAs. ${ }^{32}$ Some potential advantages of NMBAs are reduced oxygen consumption, improved $\mathrm{P}_{\mathrm{aO}}$, prevention of respiratory movements, increased chest-wall compliance, reduced inflammatory-mediator release, reduced dynamic hyperinflation, prevention of patient-ventilator asynchrony (including auto-triggering), and facilitation and maintenance of lung recruitment. Gannier and colleagues, in a prospective, controlled study with 56 patients with acute respiratory distress syndrome (ARDS), randomized to conventional therapy without NMBA or conventional therapy plus cisatracurium over 48 hours, reported improved $\mathrm{P}_{\mathrm{aO}_{2}} / \mathrm{F}_{\mathrm{IO}_{2}}$ ratio, decreased PEEP, and a decrease in peak and plateau airway pressure over time. ${ }^{33}$ In a similarly designed study of 26 patients with acute respiratory distress syndrome (ARDS), patients randomized to receive cisatracurium for 48 hours had greater improvement in $\mathrm{P}_{\mathrm{aO}_{2}} / \mathrm{F}_{\mathrm{IO}_{2}}$ and lower concentrations of pro-inflammatory mediators measured in bronchoalveolar lavage fluid. ${ }^{34}$ In a recently published multicenter double-blind trial of 340 patients presenting to the ICU with ARDS onset within the previous 48 hours, patients randomized to receive cisatracurium for 48 hours had better adjusted 90-day survival and more time off the ventilator, without increasing the muscle weakness. ${ }^{35}$

Some disadvantages of NMBAs include variable effect on $\mathrm{P}_{\mathrm{aO}}$, increased atelectasis, cephalad displacement of the diaphragm, inability to increase minute ventilation in response to need for increased carbon dioxide removal (ie, excessive caloric intake), and airway closure. Until recently the primary outcomes of NMBA have not demonstrated a benefit. Arroliga et al, in a retrospective analysis of 5,183 patients receiving mechanical ventilation for greater than 12 hours, showed that $13 \%$ of the patients received NMBAs for at least 1 day (median 2 d), and NMBA use was associated with longer mechanical ventilation (median $7 \mathrm{~d}$ vs $3 \mathrm{~d}$ ), longer ICU stay (median $10 \mathrm{~d}$ vs $7 \mathrm{~d}$ ), and higher mortality (50\%, odds ratio 1.39). ${ }^{36} \mathrm{In}$ a similar retrospective review of NMBA use in patients with acute lung injury and ARDS, NMBAs were not associated with mortality. Use of NMBAs on the first day of mechanical ventilation was associated with longer mechanical ventilation ( $13.5 \mathrm{~d}$ vs $3 \mathrm{~d}$ ) and longer time to successful 2-hour spontaneous breathing trial ( $8 \mathrm{~d}$ vs $4 \mathrm{~d}$ )..$^{2,33,34}$

The use of NMBAs in adequately sedated patients does not appear to reduce oxygen consumption or energy expenditure. In a prospective study of 32 postoperative patients requiring mechanical ventilation and sedation, increasing the depth of sedation alone reduced the resting energy expenditure and oxygen consumption. ${ }^{37}$ In a prospective randomized placebo-controlled crossover trial of 18 mechanically ventilated and sedated patients with se- vere sepsis or septic shock, NMBA at a targeted level of paralysis improved static respiratory compliance but did not affect oxygen consumption or delivery. ${ }^{38}$

NMBAs should be used with caution, due to the problems associated with their use, such as the elimination of a cough, hindrance of neurologic and psychologic evaluation, the possibility of a paralyzed patient in pain or an awake but paralyzed patient, possible danger of ventilator disconnection, possible myopathy/neuropathy, difficult and prolonged reversal, and prolonged paralysis following neuromuscular blockade. ${ }^{39-50}$ Autopsies performed on muscle from critically ill patients who were mechanically ventilated and received vecuronium prior to death demonstrated that with increasing doses of NMBA the fetal nicotinic acetylcholine receptor density increased, which is suggestive of denervation-like changes that might explain prolonged paralysis following long-term NMBA administration. ${ }^{51}$ Although occasionally refuted, ${ }^{52}$ the combination of long-term high-dose steroids and prolonged NMBA may increase the likelihood of developing an acute myopathy, with an incidence as high as 30\%.48,53-56 The use of a peripheral nerve stimulator is advisable to measure the level of neuromuscular blockade and gauge further titrations. In a prospective randomized single-blind trial of 77 critically ill patients requiring continuous NMBA, dosing guided by peripheral neuromuscular monitoring, when compared to standard clinical dosing, resulted in less drug used per hour, less total drug, and faster recovery of neuromuscular function (risk ratio 1.89) and spontaneous ventilation (risk ratio 2.27). ${ }^{52}$ As a general guideline, the use of NMBAs should be uncommon, the dose and duration minimized and guided by peripheral neuromuscular monitoring, and adequate sedation and analgesia must be provided.

Sedating the critically ill patient requires proper assessment of the degree and causes of a patient's agitation. Furthermore, the treatment of the agitation should be directed at enhancing patient comfort and safety, avoiding adverse effects by using the lowest effective dose, and minimizing cost. The Society of Critical Care Medicine's clinical practice guidelines for sustained use of sedatives and analgesics in critically ill adults recommend the use of a sedation goal or end point, regular reassessment with a validated sedation-assessment scale, and documenting the regular assessment and response to therapy. ${ }^{7}$ Sedation scales available include the Richmond Agitation-Sedation Scale and the Sedation-Agitation Scale, which are reliable and valid to assess adequacy of sedation in critically ill adults. ${ }^{57-59}$ The Riker Agitation-Sedation Scale has been validated to detect changes in sedation status over consecutive days, maintains reliability in clinical scenarios where the patient has an altered level of consciousness and delirium, and correlates with the amount of sedative and analgesic doses administered to critically ill patients. ${ }^{59}$ Use of guidelines for analgesia, sedation, and neuromuscular 
blockade in ICU patients reduces NMBA use, drug costs, the incidence of pain and agitation, nosocomial infection rate, duration of mechanical ventilation, and ICU stay. ${ }^{60,61}$ Daily interruption of continuous sedative infusion decreases the duration of mechanical ventilation and ICU stay. ${ }^{62} \mathrm{~A}$ multicenter randomized trial assessing a protocol that coupled a spontaneous awakening trial with spontaneous breathing trials found that the patients in the intervention group had more ventilator-free days during the 28-day study period ( $14.7 \mathrm{~d}$ vs $11.6 \mathrm{~d}, P=.02)$, spent fewer days in the ICU (median $9.1 \mathrm{~d}$ vs $12.9 \mathrm{~d}, P=.01$ ), and were discharged from the hospital earlier (median hospital days $14.9 \mathrm{~d}$ vs $19.2 \mathrm{~d}, P=.04){ }^{63}$ The patients in the intervention group were more likely to self-extubate (16 patients vs 6 patients, $P=.03$ ), but the re-intubation rate after self-extubation in the intervention and control groups were similar (5 patients vs 3 patients, $P=.47$ ). At any point during the year after enrollment, the patients in the intervention group were less likely to die than the patients in the control group. Disadvantages of daily sedative interruption include increased risk of ventilator asynchrony, hemodynamic instability, self-extubation, and excessive agitation.

\section{Summary}

Optimizing patient comfort and safety in the ICU plays an integral part in caring for critically ill patients. The treatment should be directed toward a specific indication, not simply to provide restraint. Utilizing standard rating scales and unit-based guidelines facilitates the proper use of sedation and NMBA. The triad of factors that lead to agitation includes pain, anxiety, and delirium. Pain is extremely common, even in medical patients. The approach to treating pain is multimodal. Anxiety can contribute to agitation, but can be treated conservatively, especially avoiding continuous infusions of benzodiazepines. Delirium is undertreated and prolongs ICU stay. Target the treatment of delirium at modifying the patient's risk factors and the use of medications, such as haloperidol and quetiapine. NMBAs should be used judiciously, but, when used, attempts should be made to limit their dose and duration of use. Patients may rehabilitate while receiving mechanical ventilation, but they will not make much progress while receiving intravenous sedation or chemical restraints. In some circumstances, no sedation can be advantageous. The ultimate goal of sedation is a calm, comfortable patient who can easily be aroused.

\section{REFERENCES}

1. Kollef MH, Levy NT, Ahrens TS, Schaiff R, Prentice D, Sherman G. The use of continuous IV sedation is associated with prolongation of mechanical ventilation. Chest 1998;114(2):541-548.

2. Arroliga AC, Thompson BT, Ancukiewicz M, Gonzales JP, Guntupalli KK, Park PK, et al. Use of sedatives, opioids, and neuromus- cular blocking agents in patients with acute lung injury and acute respiratory distress syndrome. Crit Care Med 2008;36(4):1083-1088.

3. Fraser GL, Prato BS, Riker RR, Berthiaume D, Wilkins ML. Frequency, severity, and treatment of agitation in young versus elderly patients in the ICU. Pharmacother 2000;20(1):75-82.

4. Woods JC, Mion LC, Conner JT, Viray F, Jahan L, Huber C, et al. Severe agitation among ventilated medical intensive care unit patients: frequency, characteristics and outcomes. Intensive Care Med 2004;30(6):1066-1072.

5. Chanques G, Sebbane M, Barbotte E, Viel E, Eledjam JJ, Jaber S. A prospective study of pain at rest: incidence and characteristics of an unrecognized symptom in surgical and trauma versus medical intensive care unit patients. Anesthesiology 2007;107(5):858-860.

6. Rudin A, Flisberg P, Johansson J, Walther B, Lundberg CJ. Thoracic epidural analgesia or intravenous morphine analgesia after thoracoabdominal esophagectomy: a prospective follow-up of 201 patients. J Cardiothorac Vasc Anesth 2005;19(3):350-357.

7. Jacobi J, Fraser GL, Coursin DB, Riker RR, Fontaine D, Wittbrodt ET, et al. Clinical practice guidelines for the sustained use of sedatives and analgesics in the critically ill adult. Crit Care Med 2002; 30(1):119-141.

8. Pandharipande P, Shintani A, Peterson J, Truman B, Wilkinson GR, Dittus RS, et al. Lorazepam is an independent risk factor for transitioning to delirium in intensive care unit patients. Anesthesiology 2006;104(1):21-26.

9. Strøm T, Martinussen T, Toft P. A protocol of no sedation for critically ill patients receiving mechanical ventilation: a randomised trial. Lancet 2010;375(9713):475-480.

10. Ely EW, Inouye SK, Bernard GR, Gordon S, Francis J, May L, Truman B, Speroff T, Gautam S, Margolin R, Hart RP, Dittus R. Delirium in mechanically ventilated patients: validity and reliability of the confusion assessment method for the intensive acre unit (CAMICU). JAMA 2001;286(21):2703-2710.

11. Pun BT, Ely EW. The importance of diagnosing and managing ICU delirium. Chest 2007;132(2):624-636.

12. Peterson JF, Pun BT, Dittus RS, Thomason JW, Jackson JC, Shintani AK, Ely EW. Delirium and its motoric subtypes: a study of 614 critically ill patients. J Am Geriatr Soc 2006;54(3):479-484.

13. Ely EW, Shintani A, Truman B. Delirium as a predictor of mortality in mechanically ventilated patients in the intensive care unit. JAMA 2004;291(14):1753-1762.

14. Inouye SK, Bogardus ST, Charpentier PA, Leo-Summers L, Acampora D, Holford TR, Cooney LM. A multicomponent intervention to prevent delirium in hospitalized older patients. N Engl J Med 1999; 340(9):669-676.

15. Inouye SK, Charpentier PA. Precipitating factors for delirium in hospitalized elderly persons: predictive model and interrelationship with baseline vulnerability. JAMA 1996;275(11):852-857.

16. Inouye SK, Viscoli CM, Horwitz RI, Hurst LD, Tinetti ME. A predictive model for delirium in hospitalized elderly medical patients based in admission characteristics. Ann Intern Med 1993;119(6):474-481.

17. Schweickert WD, Pohlman MC, Pohlman AS, Nigos C, Pawlik AJ, Esbrook CL, et al. Early physical and occupational therapy in mechanically ventilated, critically ill patients: a randomised controlled trial Lancet 2009;373(9678):1874-1882.

18. Bergeron N, Dubois MJ, Dumont M, Dial S, Skrobik Y. Intensive care delirium screening checklist: evaluation of a new screening tool. Intensive Care Med 2001;27(5):859-864.

19. Otter H, Martin J, Basell K, von Heymann C, Hein OV, Bollert P, et al. Validity and reliability of the DDS for severity of delirium in the ICU. Neurocrit Care 2005;2(2):150-158.

20. Inouye Sk, van Dyck CH, Alessi CA, Balkin S, Siegal AP, Horwitz RI Clarifying confusion: the confusion assessment method: a new method for detection of delirium. Ann Intern Med 1990;113(12):941-948. 


\section{When Should Sedation or Neuromuscular Blockade Be Used}

21. Kalisvaart KJ, de Jonghe JFM, Bogaards MJ, Vreeswijk R, Egberts TCG, Burger BJ, et al. Haloperidol prophylaxis for elderly hipsurgery patients at risk for delirium: a randomized placebo-controlled study. J Am Geriatr Soc 2005;53(10):1658-1666.

22. Devlin JW, Roberts RJ, Fong JJ, Skrobik Y, Riker RR, Hill NS, et al. Efficacy and safety of quetiapine in critically ill patients with delirium: a prospective, multicenter, randomized, double-blind, placebo-controlled pilot study. Crit Care Med 2010;38(2):419-427.

23. Kahn JM, Andersson L, karir V, Polissar NL, Neff MJ, Rubenfeld GD. Low tidal volume ventilation does not increase sedation use in patients with acute lung injury. Crit Care Med 2005;33(4):766-771.

24. Cheng IW, Eisner MD, Thompson BT, Ware LB, Matthay MA. Acute effects of tidal volume strategy on hemodynamics, fluid balance, and sedation in acute lung injury. Crit Care Med 2005;33(1):63-70.

25. Pohlman MC, McCallister KE, Schweickert WD, Pohlman AS, Nigos CP, Krishnan JA, et al. Excessive tidal volume from breath stacking during lung-protective ventilation for acute lung injury. Crit Care Med 2008;36(11):3019-3023.

26. Sanchez-Izquierdo-Riera JA, Caballero-Cubedo RE, Perez-Vela JL, Ambros-Checa A, Cantalapiedra-Santiago JA, Alted-Lopez E. Propofol versus midazolam: safety and efficacy for sedating the severe trauma patient. Anesth Analg 1998;86(6):1219-1224.

27. Weinbroum AA, Halpern P, Rudick V, Sorkine P, Freedman M, Geller E. Midazolam versus propofol for long-term sedation in the ICU: a randomized prospective comparison. Intensive Care Med 1997;23(12):1258-1263.

28. Aitkenhead AR, Willatts SM, Park GR, Collins CH, Ledingham IM, Pepperman ML, et al. Comparison of propofol and midazolam for sedation in critically ill patients. Lancet 1989;2(8665):704-709.

29. Drugs.com editors. FDA approves new indication for Hospira's Precedex (dexmedetomidine $\mathrm{HCl}$ ) injection. http://www.drugs.com/ newdrugs/fda-approves-new-indication-hospira-s-precedexdexmedetomidine-hcl-1166.html. Accessed December 4, 2010.

30. Pandharipande PP, Pun BT, Herr DL, Maze M, Girard TD, Miller RR, et al. Effect of sedation with dexmedetomidine vs lorazepam on acute brain dysfunction in mechanically ventilated patients: the MENDS randomized controlled trial. JAMA 2007;298(22):2644-2653.

31. Riker RR, Shehabi Y, Bokesch PM, Ceraso D, Wisemandle W, Koura $\mathrm{F}$, et al. Dexmedetomidine vs midazolam for sedation of critically ill patients: a randomized trial. JAMA 2009;301(5):489-499.

32. Kumar A, Zarychanski R, Pinto R, Cook DJ, Marshall J, Lacroix J, et al. Critically ill patients with 2009 influenza A(H1N1) infection in Canada. JAMA 2009;302(17):1872-1879.

33. Gainnier M, Roch A, Forel JM, Thirion X, Arnal JM, Donati S, Papazian L. Effect of neuromuscular blocking agents on gas exchange in patients presenting with acute respiratory distress syndrome. Crit Care Med 2004;32(1):113-119.

34. Forel JM, Roch A, Marin V, Michelet P, Demory D, Blache JL, et al. Neuromuscular blocking agents decrease inflammatory response in patients presenting with acute respiratory distress syndrome. Crit Care Med 2006;34(11):2749-2757.

35. Papazian L, Forel JM, Gacouin A, Penot-Ragon C, Perrin G, Loundou A, et al. Neuromuscular blockers in early acute respiratory distress syndrome. N Engl J Med 2010;363(12):1107-1116.

36. Arroliga A, Frutos-Vivar F, Hall J, Esteban A, Apezteguia C, Soto L, Anzueto A. Use of sedatives and neuromuscular blockers in a cohort of patients receiving mechanical ventilation. Chest 2005;128(2):496-506.

37. Terao Y, Miura K, Saito M, Sekino M, Fukusaki M, Sumikawa K. Quantitative analysis of the relationship between sedation and resting energy expenditure in postoperative patients. Crit Care Med 2003;31(3): 830-833.

38. Freebairn RC, Derrick J, Gomersall CD, Young RJ, Joynt G. Oxygen delivery, oxygen consumption, and gastric intramucosal $\mathrm{pH}$ are not improved by a computer-controlled, closed-loop, vecuronium infusion in severe sepsis and septic shock. Crit Care Med 1997;25(1):72-77.

39. Lagasse RS, Katz RI, Petersen M, Jacobson MJ, Poppers PJ. Prolonged neuromuscular blockade following vecuronium infusion. J Clin Anesth 1990;2(4):269-271.

40. Partridge BL, Abrams JH, Bazemore C, Rubin R. Prolonged neuromuscular blockade after long-term infusion of vecuronium bromide in the intensive care unit. Crit Care Med 1990;18(10):1177-1179.

41. Margolis BD, Khachikian, Friedman Y, Garrard C. Prolonged reversible quadriparesis in mechanically ventilated patients who received longterm infusions of vecuronium. Chest 1991;100(3):877-878.

42. Op de Coul AA, Lambregts PC, Koeman J, van Puyenbroek MJ, Ter Laak HJ, Gabreëls-Festen AA. Neuromuscular complications in patients given pavulon (pancuronium bromide) during artificial ventilation. Clin Neurol Neurosurg 1985;87(1):17-22.

43. Gooch JL, Suchyta MR, Balbierz JM, Petajan JH, Clemmer TP. Prolonged paralysis after treatment with neuromuscular junction blocking agents. Crit Care Med 1991;19(9):1125-1131.

44. Meyer KC, Prielipp RC, Grossman JE, Coursin DB. Prolonged weakness after infusion of atracurium in two intensive care unit patients. Anesth Analg 1994;78(4):772-774.

45. Tabarki B, Coffinieres A, Van den Bergh P, Huault G, Landrieu P, Sebire G. Critical illness neuromuscular disease: clinical, electrophysiological, and prognostic aspects. Arch Dis Child 2002;86(2):103-107.

46. Geller TJ, Kaiboriboon K, Fenton GA, Hayat GR. Vecuroniumassociated axonal motor neuropathy: a variant of critical illness polyneuropathy? Neuromuscul Disord 2001;11(6-7):579-582.

47. Segredo V, Caldwell JE, Matthay MA, Sharma ML, Gruenke LD, Miller RD. Persistent paralysis in critically ill patients after longterm administration of vecuronium. N Engl J Med 1992;327(8):524528.

48. Barohn RJ, Jackson CE, Rogers SJ, Ridings LW, McVey Al. Prolonged paralysis due to nondepolarizing neuromuscular blocking agents and corticosteroids. Muscle Nerve 1994;17(6):647-654.

49. Hoey LL, Joslin SM, Nahum A, Vance-Bryan K. Prolonged neuromuscular blockade in two critically ill patients treated with atracurium. Pharmacother 1995;15(2):254-259.

50. Vanderheyden BA, Reynolds HN, Gerold KB, Emanuele T. Prolonged paralysis after long-term vecuronium infusion. Crit Care Med 1992;20(2):304-307.

51. Dodson BA, Kelly BJ, Braswell LM, Cohen NH. Changes in acetylcholine receptor number in muscle from critically ill patients receiving muscle relaxants: an investigation of the molecular mechanism of prolonged paralysis. Crit Care Med 1995;23(5):815-821.

52. Rudis M, Sikora CA, Angus E, Peterson E, Popovich J Jr, Hyzy R, Zarowitz BJ. A prospective, randomized, controlled evaluation of peripheral nerve stimulation versus standard clinical dosing of neuromuscular blocking agents in critically ill patients. Crit Care Med 1997;25(4):575-583.

53. Road J, Mackie G, Jiang T, Stewart H, Eisen A. Reversible paralysis with status asthmaticus, steriods, and pancuronium: clinical electrophysiological correlates. Muscle Nerve 1997;20(12):1587-1590.

54. David W, Roehr C, Leatherman J. EMG findings in acute myopathy with status asthmaticus, steroids and paralytics: clinical and electrophysiologic correlation. Electromyogr Clin Neurophysiol 1998; (3896):371-376 .

55. Zochodne DW, Ramsay DA, Shelley S. Acute necrotizing myopathy of intensive care: electrophysiologic studies. Muscle Nerve 1994; 17(3):285-292.

56. Marik PE. Doxacurium-corticosterid acute myopathy: another piece to the puzzle. Crit Care Med 1996;24(7):1266-1267.

57. Riker RR, Picard JT, Fraser GL. Prospective evaluation of the Sedation-Agitation Scale for adult critically ill patients. Crit Care Med 1999;27(7):1325-1329. 
58. Sessler CN, Gosnell MS, Grap MJ, Brophy GM, ONeal PV, Keane KA, et al. The Richmond Agitation-Sedation Scale: validity and reliability in adult intensive care unit patients. Am J Respir Crit Care Med 2002;166(100):1338-1344.

59. Ely EW, Truman B, Shintani A, Thomason JW, Wheeler AP, Gordon S, et al. Monitoring sedation status over time in ICU patients: reliability and validity of the Richmond Agitation-Sedation Scale 9 (RASS). JAMA 2003;289(22):2983-2991.

60. Mascia MF, Koch M, Medicis JJ. Pharmacoeconomic impact of rational use guidelines on the provision of analgesia, sedation, and neuromuscular blockade in critical care. Crit Care Med 2000;28(7):2300-2306.
61. Chanques G, Barbotte JS, Violet S, Sebbane M, Perrigault PF, Mann $\mathrm{C}$, et al. Impact of systematic evaluation of pain and agitation in an intensive care unit. Crit Care Med 2006;34(6):1691-1699.

62. Kress JP, Pohlman AS, O'Conner MF, Hall JB. Daily interruption of sedative infusions in critically ill patients undergoing mechanical ventilation. N Engl J Med 2000;342(20):1471-1477.

63. Girard TD, Kress JP, Fuchs BD, Thomason JW, Schweickert WD, Pun BT, et al. Efficacy and safety of a paired sedation and ventilator weaning protocol for mechanically ventilated patients in intensive care (Awakening and Breathing Controlled trial): a randomised controlled trial. Lancet 2008;371(9607):126-134.

\section{Discussion}

Kacmarek: In 2009 an abstract was presented at the European Intensive Care Society meeting. Papazian et $\mathrm{al}^{1}$ presented data on 165 ARDS patients in each arm, randomized initially to 48 hours of paralysis with appropriate sedation versus sedation to apnea. They found better mortality in the paralyzed patients. But it was published only as an abstract.

1. Papazian L, Fogel JM, Gacouin A, Perrin G, Jabar S, Arnal JM, Perez D, seghboyan JM, Constantin JM, Courant P, Roch A, the ACURASYS Study Group. Systematic two-day muscle relaxants course in the early phase of severe acute respiratory distress syndrome: a multicenter randomized controlled trial (abstract). Intensive Care Medicine 2009;35;A234.

Hurford: I was not surprised, because in that patient population they were able to do a much more concerted ventilator strategy and bring down the PEEP and airway pressure, and probably to provide a different mechanical ventilation pattern that I think would create less of an inflammatory response. To read anything more into that-is it the drug per se? Probably not. Is it what the drug enables you to do? Probably so. Should there be a better way of accomplishing that same outcome that doesn't require neuroblockade? I would hope so.

Kacmarek: Since all the patients were apneic - those paralyzed and sedated, and those just sedated-he at- tributed the overall mortality difference to the impact of the drug.

Hurford: I strongly agree with that. If I can just go to non-evidence-based medicine, when I was starting out in critical care and I didn't know what I was doing as well, I could paralyze a patient, get control, get the hemodynamics and everything better much faster when I used a paralytic. For whatever reason, I don't need to do that as much any more, and whether that's due to improvements in ventilator patterns, in the other sedatives, such as propofol, or in titrating drugs more carefully, there's no question that there are times the patient is not doing well, and patient-ventilator asynchrony should be pharmacologically surpressed for a while. A couple of days is very reasonable. I can't show you any evidence that it's going to change their muscular function, provided the blockade is not prolonged, using the technique that Laurent uses. Using those drugs for a couple of weeks, though, is a different story.

Kacmarek: Yes, everything was the same in both arms-same ventilation and sedation strategy - except the use of neuromuscular blockade.

Pierson: Bill, your comment that you used a lot more paralysis earlier in your career than you do now is a very telling one, and I think a lot of us would share that same experience. It gets to one of the big themes of this conference: the issue of knowledge translation, or, stated another way, the incredible need for education of the clinicians who are managing patients in the milieu of the available evidence. Does tachypnea mean discomfort and always mandate more sedation? Does tachycardia mean pain and the need for more sedation? It seems to to many of the clinicians where I work, and I think it contributes to the "night shift phenomenon": all day long we work to reduce the amount of sedation and wake the patient up, the patient is interactive when we go home, and we come in the next morning to find that the patient has somehow had a requirement for more and more doses of everything and remains comatose for most of the day. I think it speaks to a need to take this message to the bedside, and I appreciate your ending with some practical advice to the reader.

de Wit: About 20 years ago, Hansen-Flaschen surveyed clinicians on the use of sedatives and neuromuscular blockade to facilitate patient-ventilator interactions, and they were frequently used.

1. Hansen-Flaschen JH. Brazinsky S, Basille C, Lanken PN. Use of sedating drugs and neuromuscular blocking agents in patients requiring mechanical ventilation for respiratory failure: a national survey. JAMA 1991;266(20):2870-2875.

Hurford: I would argue that it's used to facilitate the absence of the provider from the bedside.

de Wit: That may well be, but I don't know of any studies on that. A nurse may have 2 or 3 patients under their 
care and have a high concern that something adverse could happen when they leave the room. The other problem with sedation is that we assume all people should be treated equally. An analogy is that we give different antibiotics for different types of sepsis, but in the world of sedation we try to treat everyone the same way: all patients should undergo sedation interruptions; all patients should be on a sedation algorithm and managed the same way.

Within the ICU patient population the need for sedation is quite varied; some patients need no sedation. I had one patient who sat up and read an entire novel within 2 days and then was working on his laptop computer. Then there are other patients who need very high sedation and are still "bucking the ventilator." The ABC trial ${ }^{1}$ indicated that not everyone could tolerate sedation interruption: $85 \%$ of patients tolerated sedative interruption, and $90 \%$ of those tolerated opiate interruption, which means that $76 \%$ of patients could tolerate both sedative and opiate interruption. More importantly, 1 in 4 patients did not tolerate sedation interruption as proposed by Kress et al. ${ }^{2}$ So why are we letting 1 in 4 patients fail? I don't understand the reasoning for that, except that at this point we don't have different treatments. It's the experience with those 1 in 4 patients with whom the nurses are struggling that makes nurses hesitant to interrupt sedation in the other 3 in 4 patients.

1. Girard TD, Kress JP, Fuchs BD, Thomason JW, Schweickert WD, Pun BT, Taichman DB, et al. Efficacy and safety of a paired sedation and ventilator weaning protocol for mechanically ventilated patients in intensive care (Awakening and Breathing Controlled trial): a randomised controlled trial. Lancet 2008;371(9607):126134.

2. Kress JP, Pohlman AS, O'Connor MF, Hall JB. Daily interruption of sedative infusions in critically ill patients undergoing mechanical ventilation. N Engl J Med 2000;342(20):1471-1477.
Hurford: My background is as an anesthesiologist. In the operating room it would obviously be unacceptable to periodically turn everything off until the patient was awake in the middle of the operation and then turn everything back on again. It's like driving with the pedal to the metal and then slamming on the brakes: there's no titration or customization. Hence, my approach to this talk is that we need to examine the patient, assess for a diagnosis whether they're delirious, anxious, or in pain, and treat those individually and separately. My preference is to not need to turn everything off: if they're never asleep, they don't need the drug discontinued. Yes, some patients do need that for a short period, but it needs to be brought back. Our guideline is to diagnose each of those factors separately, to treat them individually, and try to get to the goal of a patient who can tolerate mechanical ventilation and not necessarily need periodic discontinuation of medications. I think discontinuation on a daily basis for everybody-it's not one-sizefits-all. I can't agree with you more.

Chatburn: Is there a standard definition for diagnosing delirium?

de Wit: The RASS [Richmond Agitation Sedation Scale] does not diagnose delirium. The CAM-ICU [Confusion Assessment Method for the Intensive Care Unit] is one tool to diagnose delirium. The Intensive Care Delirium Screening Checklist is another. Basically, delirium is characterized by acute-onset mental-status changes that wax and wane and is marked by inattention and disorganized thinking.

Hurford: Yes, the CAM-ICU, I'm told, is the one most often used around the country right now. It was validated primarily at Vanderbilt by Wes Ely's group. ${ }^{1}$

1. Ely EW, Inouye SK, Bernard GR, Gordon S, Francis J, May L, et al. Evaluation of delirium in critically ill patients: validation of the Confusion Assessment Method for the Intensive Care Unit (CAM-ICU). JAMA 2001;286(21):2703-2710.

Sassoon: Can you comment on acquired critical illness neuromyopathy? Is that more of an interaction between sepsis and neuromuscular blockade, or is it due to the neuromuscular blockade alone? My animal experiments ${ }^{1,2}$ showed the adverse effects of CMV [continuous mandatory ventilation] on the diaphragm-CMV causes acquired diaphragm muscle weakness. All patients with neuromuscular blockade require $\mathrm{CMV}$, so it stands to reason that it contributes to diaphragm muscle weakness.

1. Sassoon CS, Caiozzo VJ, Manka A, Sieck GC. Altered diaphragm contractile properties with controlled mechanical ventilation. J Appl Physiol 2002;92(6):25852595.

2. Sassoon CS, Zhu E, Caiozzo VJ. Assistcontrol mechanical ventilation attenuates ventilator-induced diaphragmatic dysfunction. Am J Respir Crit Care Med 2004; 170(6):626-632.

Hurford: It's a very complicated issue, because it affects both muscle and nerves. There's a host of literature on disuse atrophy of peripheral nerve and muscles with CMV and with immobility. Also, abnormal conditions such as sepsis or burns are associated with proliferation of extrajunctional nicotinic receptors. On top of that may be a primary syndrome of neuromuscular failure associated with multiple organ system failure, which may produce primary neurologic injury and muscle myosinolysis. The best thing I can say is that a short duration-less than 2 days - and reasonable dose of neuromuscular blocker has not been shown to be associated with extrajunctional proliferation. A longer duration of mechanical ventilation and higher doses of relaxants seem to be more associated with it. So I would say that it would be a contributing factor but not necessarily a causative factor. 
Parthasarathy: I noticed that in the no-sedation trial, ${ }^{1}$ where they just used boluses of morphine, there was a higher incidence of delirium in the intervention group. How do you reconcile that with the fact that there was a higher instance of delirium, which is supposed to be an independent predictor of duration of mechanical ventilation? Whereas in their study, even though they had a higher proportion of delirium, they achieved shorter ventilation.

1. Strøm T, Martinussen T, Toft P. A protocol of no sedation for critically ill patients receiving mechanical ventilation: a randomised trial. Lancet 2010;375(9713):475-480.

Hurford: I believe it had more to do with how they were screening and diagnosing delirium. I think they saw a difference in severity, but I'm not sure on that.

Parthasarathy: There also seems to be a resurgence of the use of hypothermia in the ICU after cardiac arrest. In a patient undergoing therapeutic hypothermia do you follow a different sedation practice, or do you not sedate them at all? How do you manage what would fall under your area of expertise? Maybe there should be a poll on how many centers currently practice therapeutic hypothermia.

Hurford: With all the protocols that I'm aware of, the patient starts out comatose and is subsequently anesthetized and given additional medication. The protocols often use neuromuscular relaxants for the duration of the hypothermia; whether that's necessary is unclear. Our protocol does not use neuromuscular blockade as a primary restraint, and it's not necessary to achieve the hypothermia. There are other therapies for shiveringdeepening the level of anesthesia is usually sufficient. The hypothermia level we're targeting is the level we used to achieve unintentionally every day in the operating room, with or without the accompaniment of neuromuscular blockers. But when you're warming and you have severe shivering, that may be one time when you might want to use a neuromuscular blocker for a brief period, certainly less than 24 hours.

Younes:* Is there any systematic information from ICUs that administer as-needed sedatives and opioids on the reasons for giving them? How often is it respiratory? And when it is respiratory, how often is it because of the endotracheal tube versus because of fighting the ventilator? If we get a perfect ventilator that gives perfect synchrony, how much are we going to reduce the use of sedation?

Epstein: Pohlman ${ }^{1}$ looked at breathstacking in a small cohort of acutelung-injury patients. They asked the nurses to record why they gave sedation, and $42 \%$ of the time it was because of patient-ventilator asynchrony. They were looking mostly at breathstacking. I don't know of any other data.

1. Pohlman MC, McCallister KE, Schweickert WD, Pohlman AS, Nigos CP, Krishnan $\mathrm{JA}$, et al. Excessive tidal volume from breath stacking during lung-protective ventilation for acute lung injury. Crit Care Med 2008;36(11):3019-3023.

Younes: That should be investigated, I think.

de Wit: Some older data from nurse and physician interviews indicated that asynchrony was one of the most common reasons for administration of sedatives and opiates.

Parthasarathy: We incorporated the behavioral pain scale in the randomized controlled trial we're doing,

\footnotetext{
* Magdy Younes MD FRCP(C) PhD, Department of Medicine, University of Manitoba, Winnipeg, Manitoba, Canada.
}

and the behavioral pain scale (which is a well validated and reproducible scale that nurses use to assess pain) has asynchrony as one of the 4 domains, so if there's asynchrony, they construe that to count towards pain.

de Wit: And so too does the RASS. A RASS of +2 is marked by frequent nonpurposeful movement or asynchrony.

Kacmarek: The problem is that if you examine the behavior of staff who work nights, their reflex is to sedate, as opposed to trying to resolve the primary cause of asynchrony. I think the message we should be sending from this meeting is that many patients who experience asynchrony can be managed without sedation and that sedation shouldn't be number one on your list: it should be the last thing on your list. All the potential causes of agitation and asynchrony should be addressed before you consider sedation. That's a tough mindset to break, because it's easier for the nightshift nurses and therapists to deal with sedated patients than non-sedated patients.

Parthasarathy: That's true. Troubleshooting the ventilator is more complicated than giving a bolus of morphine. We don't have data on the effects of ventilation modes on outcomes, but Putensen ${ }^{1}$ studied APRV [airway pressure release ventilation], and I think there was less sedative administered and shorter mechanical ventilation.

1. Putensen C, Zech S, Wrigge H, Zinserling J, Stüber F, Von Spiegel T, Mutz N. Longterm effects of spontaneous breathing during ventilatory support in patients with acute lung injury. Am J Respir Crit Care Med 2001;164(1):43-49.

Kacmarek: Yes, that study did show that, but you've got to remember the protocol. They set the ventilator exactly the same in both arms, except that the patients in the non-APRV arm 
were paralyzed for 72 hours and then they put them on APRV. So they tested paralysis for 3 days versus non-paralysis in a group of patients without ARDS. The only thing I can take from that study is don't paralyze the average mechanically ventilated patient for 3 days and then expect them to do as well as patients who weren't paralyzed. Those weren't ARDS patients: they were mostly mildly injured patients at the time they entered the study.

MacIntyre: I asked him [Putensen] a number of years ago why he paralyzed everybody in the control arm and is that a legitimate control group? Is that standard of care? He said that in his institution it is standard of care to paralyze everybody, so if that is your practice, you're going to use that as your control group.

Epstein: On the issue of sedation and asynchrony, one thing I suspect is a problem, Sai, in your study, and in the RASS, is how asynchrony is defined. It may just be that a nurse or a physician diagnosed asynchrony when there was tachypnea in a mechanically ventilated patient, rather than using some of the criteria that we've tried to outline here.

Parthasarathy: That's very true. I think that kind of information is not available in real time or to an inexperienced or untrained person. In fact, there's nobody in the hospital at that point in time: it's either an intern or a resident or the nurse. We might want nurses to get trained in reading ventilator graphics, but we're having difficulty getting ourfellows trained in ventilator graphics. It's a huge problem.

Kallet: To add to that, nurses primarily diagnose asynchrony either by tachypnea or the patient popping-off (pressure-cycling) the ventilator. I have a feeling that a lot of times coughing is related to suctioning or turning or other things that may produce transient asynchrony but that are not nec- essarily indicative that the ventilator is set inappropriately for most of the time.

Gentile: Bill, I'd like to hear your take on BIS [bispectral index] monitoring in the ICU, because it sort of gives us a target in something objective, versus subjective with a lot of the scoring systems.

Hurford: There's a reason I didn't have that in the talk. I had to be straightforward and say there are no data to support its use in the ICU, or I could shut up —and at this point, I probably should. The question is, what number do you aim for? Is the initial number useful? Theoretically, yes, it' d be wonderful to be able to have a good-quality EEG [electroencephalogram] that would reflect the wake/sleep state. The point is that the vast majority of folks that we're treating already have an abnormal EEG. The EEG changes in relationship to the various drugs we're giving them is unclear, and the changes in BIS monitoring are very difficult to relate in the critically ill population. Even getting decent signals with the current technology is difficult. The BIS monitor also looks at EMG [electromyogram[, so the presumption for its use is that the patient's EMG is basically zero. When the monitor senses EMG, it will reflect that with a higher BIS value. Indeed, what you'll see is that a patient moving will have a high BIS value, but it doesn't necessarily mean the patient is awake.

When I use BIS monitoring I use it as a confirmation in patients who are pharmacologically paralyzed, to check if I'm missing anything. If you're giving them enough sedation, the BIS is 30 (and it's always 30 in these situations, it seems). I think it reassures, rightly or wrongly, the medical staff and the family that the patient is comfortable. See? I have this fancy monitor. I'm not sure if what I'm doing is science, but it makes folks feel better. In large clinical studies, yes, I'm sure you can get a BIS value to correlate reasonably well with a RASS score or a Ramsay Sedation Score, but whether it's valuable to the patient and worth the expense is very unclear to me. We do not do it routinely.

Parthasarathy: I totally agree. I think I would only use it in a paralyzed patient to make sure they're adequately sedated. Watson ${ }^{1}$ found that the EEG burst suppression derived by this monitor was associated with higher mortality risk. Some studies, in both ambulatory and ICU populations, have tried to correlate them with sleep stages and had better success in the ambulatory patients than the ICU patients. It almost seems like it's a device trying to find a role for itself outside of the operating room in the ICU. If you were doing daily sedation interruptions and keeping the patient right where they are and letting them surface, it seems like something you might want to rethink. The second problem is that it's got proprietary "black-box" software, so we really don't know what it's looking at. I'm all for neural monitoring in the ICU, be it someone who is paralyzed or not, but that is still a nascent field. It's an amazing field, but the proprietariness of some of this black-box stuff makes it even more difficult to accept it at this stage.

1. Watson PL, Shintani AK, Tyson R, Pandaripande P, Pun BT, Ely EW. Presence of electroencephalogram burst suppression in sedated, critically ill patients is associated with increased mortality. Crit Care Med 2008; 36:3171-3177.

de Wit: In our sedation-interruption study we used BIS monitoring right when sedation was interrupted and again when the patients were "awake." We found no difference in the BIS [unpublished data]. Also, part of the problem may be electrical interference. There was one spot in the office where we could get a paperclip to have a BIS score of 100 .

Parthasarathy: The first time BIS was introduced to me in a demonstra- 
tion, I stuck it on my medical student's forehead and he had a score of 60. I didn't know if it was the student or what. We've noticed patients who were awake in the ICU but their EEG waves were slow because they still have this slew of sedatives going into them. So I'm not surprised if the device is just looking at the spectral analysis and EMG tone and thinks they're asleep when they're actually awake. Or are they indeed awake behaviorally?

de Wit: Behaviorally, the patients were indeed awake. Patients with delir- ium develop diffuse slow-wave activity, which looks different than an awake EEG. So is the BIS not able to read delirium as awake and so you get a lower score because of the diffuse slow-wave activity? With the prevalence of delirium being so high, is that why one does not get a change in signal?

Parthasarathy: It's just not delirium. It's the residual effects of the sedatives and what the sedatives do to the EEG activity in the brain. I had a patient in the sleep lab who had a distant history of viral encephalitis and we had a really hard time scoring his EEG. We couldn't tell when he was asleep or awake, and he was having these central apneas without the crescendo/decrescendo pattern. And this was an old, burnt-out viral encephalitis that he had suffered when he was in the Korean War. Here he was with diffuse, low EEG activity, and talking, behaviorally intact, with some dementia and central apneas. I don't think the speed of EEG activity will tell us what's really happening in the brain.

This article is approved for Continuing Respiratory Care Education credit. For information and to obtain your CRCE

(free to AARC members) visit

\section{RCJournal.com}

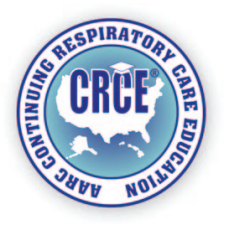

